\title{
Synthesis, computational studies, inelastic neutron scattering, infrared and Raman spectroscopy of ruthenocene
}

\author{
Stewart F. Parker and lan R. Butler
}

\section{Published version information}

This is the peer reviewed version of the following article:

SF Parker and IR Butler. 'Synthesis, computational studies, inelastic neutron scattering, infrared and Raman spectroscopy of ruthenocene.' European Journal of Inorganic Chemistry, vol. 2019, no. 8 (2018): 1142-1146.

DOI: $\underline{10.1002 / e j i c .201800914}$

which has been published in final form at DOI above. This article may be used for non-commercial purposes in accordance with Wiley-VCH terms and conditions for self-archiving.

Please cite only the published version using the reference above. This is the citation assigned by the publisher at the time of issuing the AAM. Please check the publisher's website for any updates. 


\title{
Synthesis, computational studies, inelastic neutron scattering, infrared and Raman spectroscopy of ruthenocene
}

\author{
Stewart F. Parker, ${ }^{*[a]}$ and lan R. Butler ${ }^{[b]}$
}

\begin{abstract}
In this work we report a new and simplified synthesis of ruthenocene that prevents the formation of unwanted by-products. We have also revisited the vibrational spectroscopy of this iconic molecule and in addition to infrared and variable temperature Raman spectra, we present the first inelastic neutron scattering (INS) spectrum, a technique that is little used in inorganic chemistry. The Raman spectra in the low energy range $\left(<200 \mathrm{~cm}^{-1}\right)$ clearly show that the mode assigned as the ring-Ru-ring torsion is a librational mode. By generating the INS spectra predicted by previous assignment schemes, we are able to show that they are all, at least partially, wrong because they fail to correctly predict the experimental INS spectrum. In the case of ruthenocene, the addition of INS data, in combination with periodic-DFT calculations, has enabled the first correct assignment of the internal modes of ruthenocene. This straightforward means to test proposed assignments is one of the great strengths of vibrational spectroscopy with neutrons.
\end{abstract}

\section{Introduction}

The discovery of ferrocene ${ }^{[1]}$ and the recognition ${ }^{[2]}$ of its unprecedented bis $-\eta^{5}$ mode of coordination marked the beginning of modern organometallic chemistry. It was very quickly realised ${ }^{[3]}$ that ruthenium and osmium should form analogous compounds and the preparation of $b i s-\eta^{5}$-cyclopentadienyl ruthenium (ruthenocene ${ }^{[3]}$ ) and bis- $\eta^{5}$-cyclopentadienyl osmium (osmocene ${ }^{[4]}$ ) soon followed.

The vibrational spectroscopy of all three compounds has been characterised, e.g. ${ }^{[5]}$ with ferrocene being the most studied. However, the spectroscopy is complicated by selection rules. These are irrelevant for inelastic neutron scattering (INS) spectroscopy, ${ }^{[6]}$ a technique that is little used in inorganic and organometallic chemistry. It has the advantage that, in principle, all the modes are observable. In practice, the spectra are dominated by modes involving hydrogen motion and, for instrumental reasons, the optimal spectral range is $0-1600 \mathrm{~cm}$ ${ }^{1}{ }^{[7]}$ To date, only ferrocene has been investigated by INS spectroscopy. ${ }^{[8]}$

Literature methods for the synthesis of ruthenocene are complex involving either a Grignard reagent ${ }^{[3]}$ or the preparation of sodium cyclopentadienyl..$^{\left[{ }^{[]}\right.}$In this work, we present a new and

\footnotetext{
[a] Dr Stewart F. Parker

ISIS Facility

STFC Rutherford Appleton Laboratory

Chilton, Didcot, Oxon OX11 0QX, UK

E-mail: stewart.parker@stfc.ac.uk

[b] Dr lan. R Butler

School of Chemistry

Bangor University

Bangor, Gwynedd, Wales, LL57 2UW, UK

Supporting information for this article is given via a link at the end of the document.
}

much simpler synthesis of ruthenocene together with a detailed spectroscopic characterization of the solid state spectra by infrared, Raman and INS spectroscopies. A complete assignment is made via periodic density functional theory (periodic-DFT). All previous work has relied on isolated molecule calculations ${ }^{[10]}$ that neglect the effect of the solid state.

\section{Results and Discussion}

\section{Synthesis}

As mentioned, there are many synthetic routes to ruthenocene which essentially use the reaction of a metal or metalloid cyclopentadienide with a suitable ruthenium (II) or (III) complex ${ }^{[3,11]}$ When $\mathrm{Ru}$ (III) is used, a reducing agent is also required. In our labs the method of choice is one developed inhouse in 1981 which is essentially a variant of one of the general published synthetic methods. ${ }^{[12]}$ The method is shown in Scheme 1. This uses hydrated ruthenium trichloride, freshly cracked dicyclopentadiene (to give cyclopentadiene) and powdered zinc, as the reducing agent. The difference of our method is that the reaction is performed in ethanol at low temperature. What is of interest in this synthetic route is that the deep blue color attributed to an initially formed ruthenocenium complex, is discharged rapidly, $(<0.1 \mathrm{~s})$ on warming from $-60^{\circ} \mathrm{C}$ to room temperature to leave a clear solution with only the grey colloidal zinc remaining. Thus, the reduction step is clearly observable. The workup is essentially the same as the method used by Porri et al. ${ }^{[12 a]}$, which involves crystallization of the colorless iridescent ruthenocene

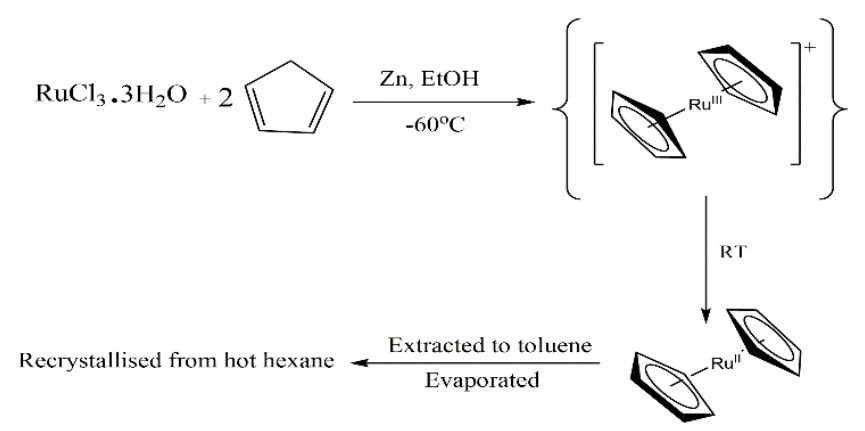

Scheme 1. Synthesis of ruthenocene. The intermediate ruthenocenium ion is not isolated.

from ethanol. By removing the need for heating the solution, unwanted by-products are not formed (see Figures S1 and S2) and yields are higher. The reaction is carried out typically on a 5$10 \mathrm{~g}$ scale of ruthenium trichloride trihydrate but is fully scaleable to the ten's of gram scale. 


\section{Vibrational Spectroscopy}

Figure 1 shows the infrared, Raman and INS spectra of ruthenocene. The complementarity of the three techniques is readily apparent and emphasizes the need for all three in order to observe all of the modes. Our infrared and Raman data are in complete agreement with that of Adams and Fernando ${ }^{[13]}$ and of Bodenheimer and Low. ${ }^{[14]}$ The INS spectrum has not been previously reported. The complete $\left(0-3200 \mathrm{~cm}^{-1}\right)$ Raman spectra as a function of temperature are shown in Figures S3 and S4 of the Supporting Information.

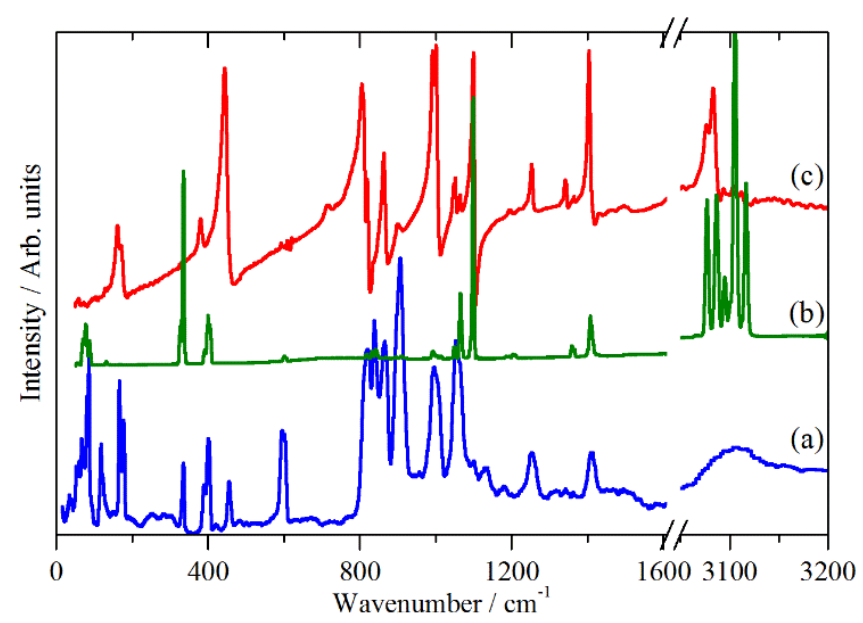

Figure 1. Vibrational spectra of ruthenocene: (a) infrared at room temperature, (b) Raman at $10 \mathrm{~K}$ and (c) INS at $10 \mathrm{~K}$.

One of the most problematic modes to assign has been the ring-Ru-ring torsion. This was assigned at $134 \mathrm{~cm}^{-1},[13,14]$ although it was recognized that the temperature dependence was anomalous: unlike all the other internal modes this undergoes a marked shift on cooling. The low energy region is shown in detail in Figure 2 and the shift in the mode from $106 \mathrm{~cm}^{-1}$ at $300 \mathrm{~K}$ to $131 \mathrm{~cm}^{-1}$ at $10 \mathrm{~K}$ is clearly seen. However, a similar temperature dependence is seen for the lattice modes at $40-100 \mathrm{~cm}^{-1}$, consistent with the shrinkage in the unit cell volume ${ }^{[15]},\left(818 \AA^{3}\right.$ at $300 \mathrm{~K}$ and $789 \AA^{3}$ at $101 \mathrm{~K}$ ), and we assign the $131 \mathrm{~cm}^{-1}$ mode to a libration. The detailed assignment of the internal modes of ruthenocene is considered in the next section.

\section{Assignment of the Spectra}

There have been several previous assignments of the vibrational spectra of ruthenocene $e^{[5,10,13,14]}$ and these are summarized in columns $4-7$ of Table 1 . It is apparent that there is no consensus between the assignments. Comparison of observed and calculated INS spectra is a very stringent test of an assignment scheme. ${ }^{[6]}$ We have previously shown that while the transition energies are very dependent on the quality of the calculation, the atomic displacements of each atom in the mode are relatively insensitive, so long as the calculated geometry is reasonably correct. ${ }^{[16]}$ This means that the INS spectrum can be simulated by replacing the calculated transition energies with those from the literature on a mode-by-mode basis. Figure 3 shows the results for the literature assignments in Table 3 . It can be seen that none of the calculated spectra match the experimental data. All fail to reproduce the very strong feature at $\sim 900 \mathrm{~cm}^{-1}$, this is probably because there are only very weak features at this energy in the Raman and infrared spectra, Figure $1 \mathrm{~b}, \mathrm{c}$, so were not considered to be fundamentals. In contrast, the intensity in the $1200 \mathrm{~cm}^{-1}$ region is overestimated because weak modes in this region were assigned as fundamentals. Figure 1a

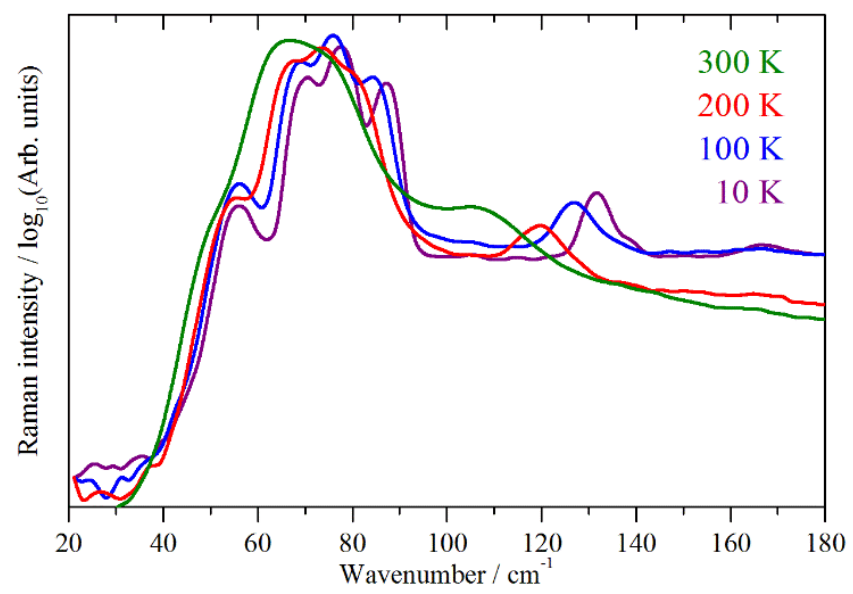

Figure 2. Variable temperature $532 \mathrm{~nm}$ Raman spectra of ruthenocene in the low energy region. Note the $y$-axis is logarithmic.

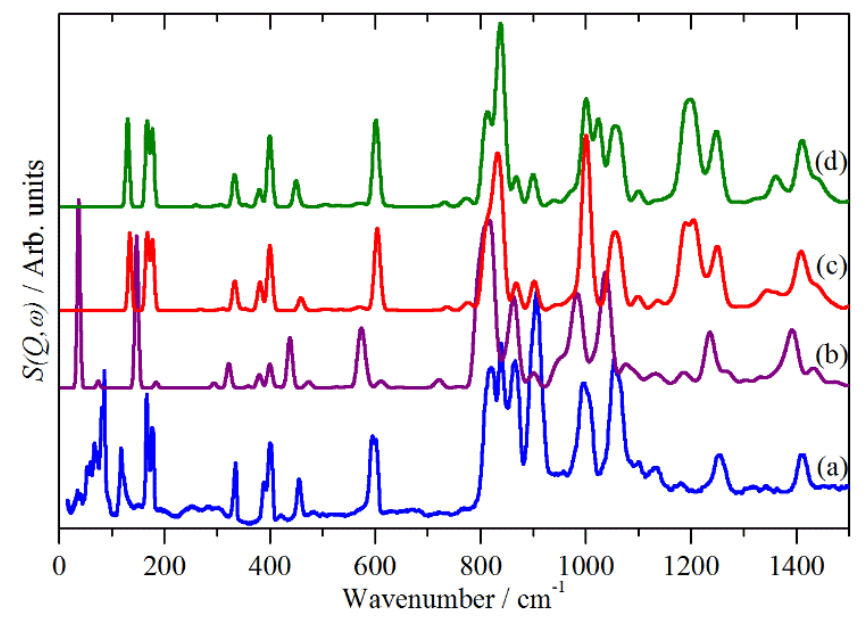

Figure 3. Comparison of INS spectra of ruthenocene: (a) experimental and those calculated from the assignment of (b) Prosenc et al, ${ }^{[10 a]}$ (c) Adams and Fernando ${ }^{[13]}$ and (d) Bodenheimer and Low ${ }^{[14]}$

shows that there are only overtones and combinations at this energy. As shown in the previous section, the assignment of the torsional mode to the feature at $\sim 130 \mathrm{~cm}^{-1}$ is clearly erroneous.

From Figure 3, it is apparent that assignments based on neither empirical correlations ${ }^{[13,14]}$ or isolated molecule DFT calculations $^{[10 a]}$ are able to reproduce the data successfully. To address this problem, we have carried out a periodic-DFT calculation of the complete orthorhombic unit cell, (space group $P$ nma $\left.{ }^{[15]}\right)$. The isolated molecule has $D_{5 h}$ symmetry, however, fivefold symmetry is incompatible with long range order and in the crystal, the molecule occupies a site of $C_{s}$ symmetry. The correlation scheme (reproduced from [14]) is shown in Figure S5 of the Supporting Information. The calculated transition energies for the complete unit cell, together with the mode number and 
symmetry of the "parent" mode under $D_{5 h}$ symmetry, are given in Table S1 of the Supporting Information. In most cases, the factor group splitting is small, $\sim 10 \mathrm{~cm}^{-1}$ or so, the only exception is mode 14 , an out-of-plane $\mathrm{C}-\mathrm{H}$ deformation, which shows a very large splitting of $50 \mathrm{~cm}^{-1}$. We have no explanation for this anomaly.

In Figure 4, we compare the results of the periodic-DFT calculation of the complete orthorhombic unit cell, $4 b$, with the experimental spectrum, 4a. It is immediately obvious that there is a much better match. The only area of serious disagreement is around $800 \mathrm{~cm}^{-1}$, where a doublet rather a triplet is observed. By slightly shifting the calculated transition energies to match the experimental ones, Figure $4 \mathrm{c}$ is obtained. It can be seen that for the internal modes the agreement is almost exact. Column 7 of Table 1 lists the average values of the transitions from Table S1. It can be seen that the "best fit" values of column 8 of Table 1 are in close agreement with those from the periodic-DFT calculation, column 7. Note that column 8 contains experimental values.

Inspection of Table 1, shows that our best fit values are in disagreement with previous assignments in several respects. The reasons for some of these have already been discussed: the bands at $900 \mathrm{~cm}^{-1}$ were not considered to be fundamentals, the INS spectrum shows unambiguously that this is the case. Conversely, the bands around $1200 \mathrm{~cm}^{-1}$ assigned as fundamentals are not. This is seen in the INS spectrum and also in the infrared and Raman spectra calculated by CASTEP, see Figures 5 and 6 respectively. These only include fundamentals (since the calculation assumes the harmonic approximation and overtones and combinations result from anharmonicity) and there is no intensity at $1200 \mathrm{~cm}^{-1}$.

Table 1. Mode description, symmetry and transition energies $\left(\mathrm{cm}^{-1}\right)$ for ruthenocene.

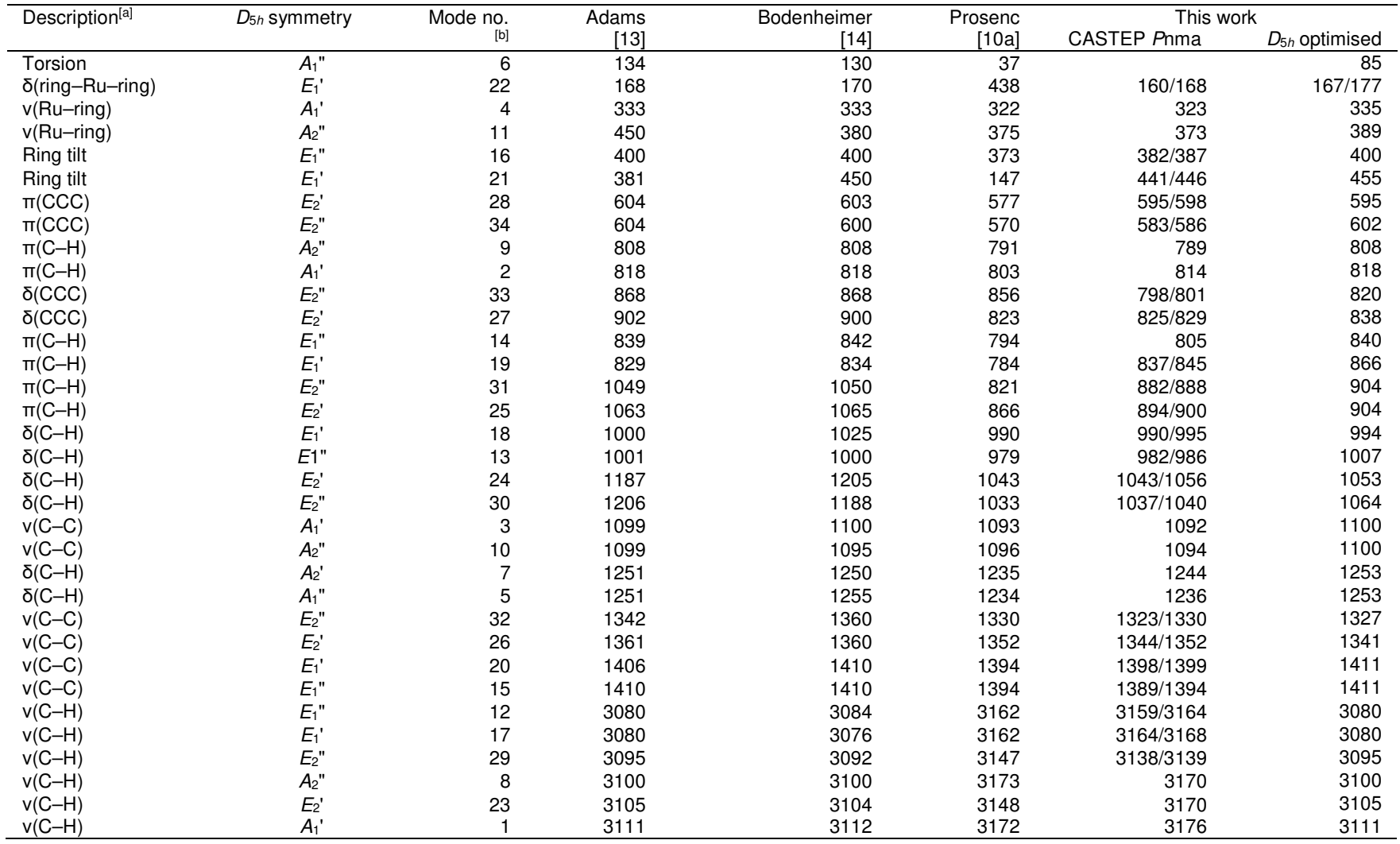

$\left.{ }^{[a}\right]_{V}=$ stretch, $\delta=$ in-plane bend, $\pi=$ out-of-plane bend

[b]The mode numbering is that used by refs. [11] and [12]. 


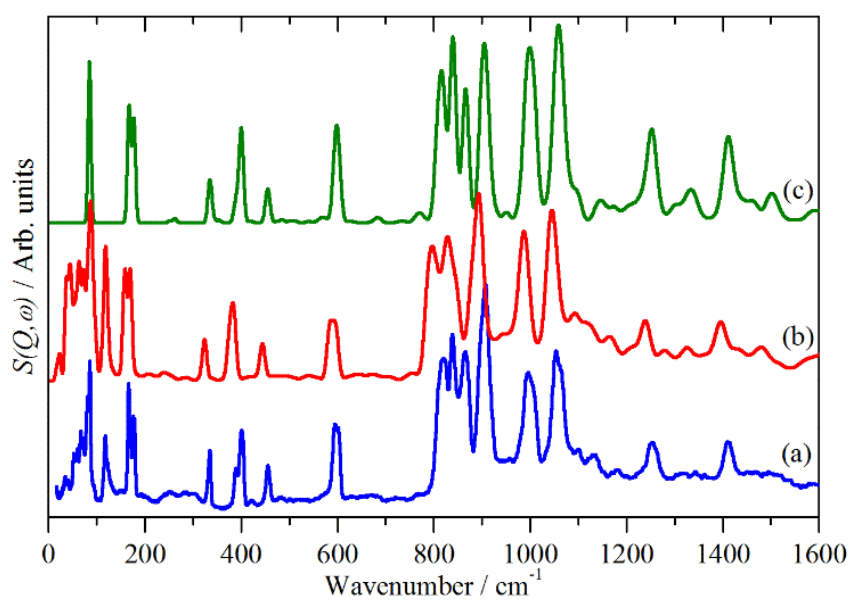

Figure 4. Comparison of INS spectra of ruthenocene: (a) experimental and those calculated by periodic-DFT calculation of the complete unit cell (b) and (c) after scaling the transition energies.

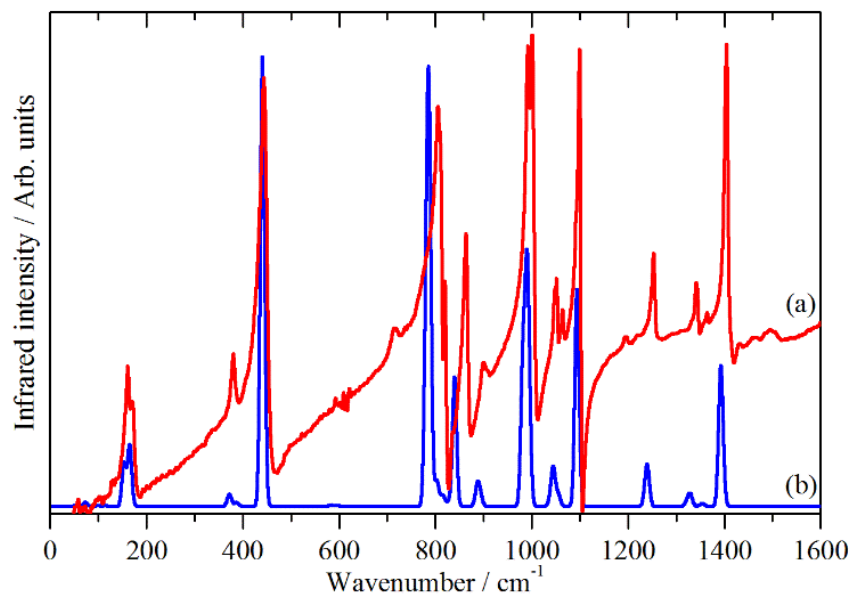

Figure 5. Comparison of infrared spectra of ruthenocene: (a) experimental and (b) calculated by periodic-DFT calculation of the complete unit. The derivativelike linehape in (a) is a particle size effect.

The most contentious assignments are for the metal-ring vibrations. There are five of these: symmetric and asymmetric (with respect to the horizontal mirror plane in the isolated molecule) Ru-ring stretch $\left(\mathrm{v}_{4}, A_{1}{ }^{\prime}\right.$ and $\left.\mathrm{v}_{11}, A_{2}{ }^{\prime \prime}\right)$ and Ru-ring tilt $\left(\mathrm{v}_{16}\right.$ $E_{1}^{\prime \prime}$ and $\left.\mathrm{v}_{21}, E_{1}^{\prime}\right)$ and the ring-Ru-ring bend $\left(\mathrm{v}_{22}, E_{1}^{\prime}\right)$. The symmetric Ru-ring stretch $\left(\mathrm{V}_{4}, A_{1}{ }^{\prime}\right)$ at $335 \mathrm{~cm}^{-1}$ is unambiguously assigned by its polarization characteristics in both solution and the solid. ${ }^{[13]}$ It has been claimed ${ }^{[10 a]}$ that the Ru-ring tilt $\left(v_{21}, E_{1}{ }^{\prime}\right)$ and the ring-Ru-ring bend $\left(\mathrm{v}_{22}, E_{1}^{\prime}\right)$ are so mixed that the distinction between them is arbitrary. This is not correct. The ring$\mathrm{Ru}$-ring bend mode involves predominantly changes in the $\mathrm{C}-\mathrm{Ru}-\mathrm{C}$ bond angles with little change in the $\mathrm{Ru}-\mathrm{C}$ bond lengths

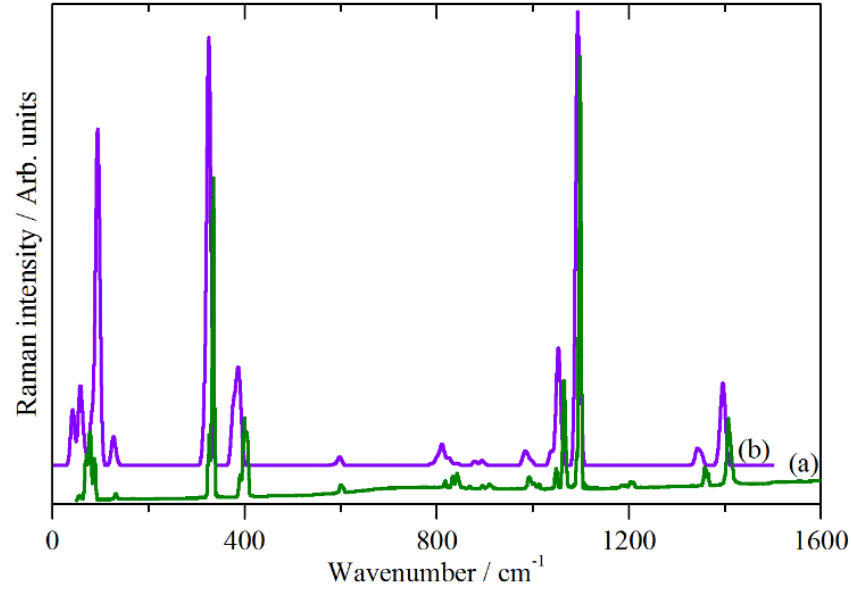

Figure 6. Comparison of Raman spectra of ruthenocene: (a) experimental and (b) calculated by periodic-DFT calculation of the complete unit.

and the reverse for the Ru-ring tilt mode. Inspection of the atomic displacements shows that for the mode at $\sim 170 \mathrm{~cm}^{-1}$, the C-RuC bond angles change by $\pm 3^{\circ}$ with only $\mathrm{a} \pm 0.01 \AA$ change in the $\mathrm{Ru}-\mathrm{C}$ bond length. While for the mode at $\sim 450 \mathrm{~cm}^{-1}$, the $\mathrm{C}-\mathrm{Ru}-\mathrm{C}$ bond angles change by $< \pm 0.5^{\circ}$ and the $\mathrm{Ru}-\mathrm{C}$ bond length by \pm $0.05 \AA$. Thus the $170 \mathrm{~cm}^{-1}$ mode must be the ring-Ru-ring bend $\left(v_{22}, E_{1}^{\prime}\right)$ and the $450 \mathrm{~cm}^{-1}$ mode the Ru-ring tilt $\left(v_{21}, E_{1}^{\prime}\right)$. The other ambiguity has been between the asymmetric $\mathrm{Ru}$-ring stretch $\left(\mathrm{v}_{11}, A_{2}^{\prime \prime}\right)$ and the Ru-ring tilt $\left(\mathrm{v}_{21}, E_{1}^{\prime}\right)$. Inspection of the mode visualizations confirms that the asymmetric $R u$-ring stretch is at $389 \mathrm{~cm}^{-1}$ and, as previously discussed, that the Ru-ring tilt $\left(v_{21}, E_{1}^{\prime}\right)$ is at $450 \mathrm{~cm}^{-1}$. This is also apparent from the simulation of the predicted spectra, Figure 3. We agree with the assignments of Bodenheimer and Low ${ }^{[14]}$ in this region and it can be seen that Figure $3 d$ is the only one that agrees with the experimental spectrum, Figure $3 a$.

The only remaining uncertainty is the location of the torsional mode. The mode visualizations show that the four factor group components are at $42,58,110$ and $114 \mathrm{~cm}^{-1}$, Table S1. The parent mode, $v_{6}, A_{1}$ " is infrared and Raman forbidden under $D_{5 h}$ symmetry, in the crystal it is allowed, but the induced activity is very small.

All previous work has implicitly used an isolated molecule model, whereby to satisfy the invariance of the center-of-mass of the system undergoing the motion (a condition for a normal mode), motion in one ring generates motion in the second ring. In the solid state, this requirement is more subtle: it is that the center-ofmass of the unit cell is invariant for an optic mode. Thus for a system that has more than one molecule in the primitive cell, such as ruthenocene $(Z=4)$, motion in one entity can be compensated by motion in another. For ruthenocene this means that only one ring of a molecule may be active in a given mode. Visualisation of the $\sim 130 \mathrm{~cm}^{-1}$ mode, confirms that this is the case here and that it is a libration. 


\section{Conclusions}

In this work we report a simplified synthesis of ruthenocene and we have also revisited the vibrational spectroscopy of this iconic molecule. The addition of INS data in combination with periodicDFT calculations has enabled the first correct assignment of the internal modes of ruthenocene. By generating the INS spectra predicted by previous assignment schemes we are able to show that they all fail to correctly predict the experimental INS spectrum. This straightforward means to test proposed assignments is one of the great strengths of vibrational spectroscopy with neutrons.

\section{Experimental Section}

Materials: The synthesis of ruthenocene is described in the main text. Ruthenium trichloride hydrate was obtained from Johnson-Matthey and the zinc dust used was standard laboratory grade.

Vibrational spectroscopy: Variable temperature, 10 - $300 \mathrm{~K}$, Raman spectra were recorded using $532 \mathrm{~nm}$ excitation with a modified Renishaw InVia system that has been previously described. ${ }^{[17]}$ Infrared spectra were recorded using a Bruker Vertex70 FTIR spectrometer, over the range 100 to $4000 \mathrm{~cm}^{-1}$ at $4 \mathrm{~cm}^{-1}$ resolution with a DLaTGS detector using 64 scans and the Bruker Diamond ATR. The use of the ultra-wide range beamsplitter enabled the entire spectral range to be recorded without the need to change beamsplitters. The spectra have been corrected for the wavelength-dependent variation in path length using the Bruker software. The INS spectrum was recorded at $<20 \mathrm{~K}$ using TOSCA ${ }^{[18]}$ at ISIS. ${ }^{[19]}$ The spectrum is available at the INS database: http://wwwisis2.isis.rl.ac.uk/INSdatabase/.

Computational studies: The plane wave pseudopotential based program CASTEP was used for the calculation of the vibrational transition energies and their intensities. ${ }^{[20,21]}$ Dispersion corrected density functional theory (DFT-D) calculations using the Tkatchenko and Scheffler[22] correction were carried out with the generalised gradient approximation (GGA) Perdew-Burke-Ernzerhof (PBE) functional in conjunction with optimised norm-conserving pseudopotentials. All of the calculations were converged to better than $|0.0075| \mathrm{eV} \AA^{-1}$. After geometry optimisation, the vibrational spectra were calculated in the harmonic approximation using densityfunctional perturbation-theory. ${ }^{[23]}$ This procedure generates the vibrational eigenvalues and eigenvectors, which allows visualisation of the modes within Materials Studio ${ }^{[24}$ and is also the information needed to calculate the INS spectrum using the program ACLIMAX. ${ }^{[25]}$ The initial structure for the optimisation was that determined at $100 \mathrm{~K} \cdot{ }^{[15 c]}$ This consistently resulted in one imaginary mode, irrespective of the convergence criteria used. Allowing both the lattice and the geometry to optimise resulted in a structure that was $<1 \%$ larger $\left(796.3 \AA^{3}\right.$ vs $\left.789.8 \AA^{3}\right)$ and with no imaginary modes anywhere in the Brillouin zone, Figure S4. An isolated molecule calculation was generated by taking the optimised structure and removing three molecules from it. The eigenvectors from this were then used with the transition energies from Table 1 to generate Figures 3b,c,d and 4c.

\section{Acknowledgements}

The STFC Rutherford Appleton Laboratory is thanked for access to neutron beam facilities. Computing resources (time on the SCARF compute cluster for the CASTEP calculations) were provided by STFC's e-Science facility. Dr Dan Evans (Bangor University) is thanked for measuring the nmr spectra.

[1] a) T. J. Kealy, P. L. Pauson, Nature, 1951, 168, 1039; b) S. A. Miller, J. A. Tebboth J. F. Tremaine, J . Chem. Soc. Resumed 1952, 632-635.

[2] G. Wilkinson, M. Rosenblum, M. C. Whiting, R. B. Woodward, J. Amer. Chem. Soc. 1952, 74, 2125-2126.

[3] G. Wilkinson, J. Amer. Chem. Soc. 1952, 74, 6146-6147.

[4] E. O. Fischer, H. Grumbert, Chem. Ber. 1959, 92, 2302-2309.

[5] B. V. Lokshin, V. T. Aleksanian, E. B. Rusach, J. Organomet. Chem. 1975, 86, 253-256.

[6] P. C. H. Mitchell, S. F. Parker, A. J. Ramirez-Cuesta, J. Tomkinson, Vibrational spectroscopy with neutrons, with applications in chemistry, biology, materials science and catalysis, World Scientific, Singapore, 2005.

[7] S. F. Parker, D. Lennon. P.W. Albers, Appl. Spec. 2011, 65, 13251341.

[8] a) E. Kemner, I. M. de Schepper, G. J. Kearley, U. A. Jayasooriya, J. Chem. Phys. 2000, 112, 10926-10929; b) U. A. Jayasooriya, S. A. Malone, A. I. Chumakov,R. Rüffer, A. R. Overweg, C. R. Nicklin, ChemPhysChem 2001, 2, 177-180.

[9] D. E. Bublitz, W. E. McEwen, and J. Kleinberg, Org. Synth. 1961, 41, 96-99.

[10] a) M. H. Prosenc, H. Reddmann, H.-D. Amberger, Spectrochimica Acta Part A, 2012, 87, 126-134; b) C. Latouche, F. Palazzetti, D. Skouteris, V. Barone, J. Chem. Theory Comput. 2014, 10, 4565-4573.

[11] a) M. D. Rausch, E. O. Fischer, H. Grubert, J. Amer. Chem. Soc.,1960, 82, 76-82. b) G.J. Gauthier, J. Chem Soc., D: Chem. Comm., 1969, 13, 690. c) D. C. Liles, A. Shaver, E. Singleton, Eric; M. B., J. Organomet. Chem. 1985, 288, C33-C36.d) M. O. Albers, D.C, Liles, D.J. Robinson, A. Shaver,E. Singleton,M. B. Wiege, J. C. A. Boeyens, D.C. Levendis, Organometallics, 1986, 5, 2321-7.e) C. H. Winter, S. Pirzad, D, H, Cao, J. Chem. Soc., Chem. Comm., 1991, 1026-.7.

[12] a) P. Pertici, G. Vitulli,,L. Porri, J. Chem. Soc., Chem. Comm, 1975, 846. b) A. Z. Rubezhov, A. S. Ivanov, A. A. Bezrukova, Izv. Akad. Nauk SSSR, Ser. Khim., 1979, 1606-8.

[13] D. M. Adams, W. S. Fernando, J. Chem. Soc. Dalton 1972, 2507-2511.

[14] J. S. Bodenheimer, W. Low, Spectrochimica Acta Part A 1973, 29, 1733-1743

[15] a) G. L. Hardgrove, D. H. Templeton, Acta Cryst. 1959, 12, 28-32; b) P. Seiler, J. D. Dunitz, Acta Cryst. 1980, B36, 2946-2950; c) A. O. Borissova, M. Yu. Antipin, D. S. Perekalin, K. A. Lyssenko, CrystEngComm 2008, 10, 827-832; d) Y Miyamoto, S. Takamizawa, Dalton Trans. 2015, 44, 5688-5691.

[16] J. Tomkinson, S. F. Parker, Spectrochimica Acta Part A 2011, 79, 2017-2019.

[17] M. A. Adams, S.F. Parker, F. Fernandez-Alonso, D.J. Cutler, C. Hodges, A. King, Appl. Spec. 2009, 63, 727-732.

[18] S. F. Parker, F. Fernandez-Alonso, A. J. Ramirez-Cuesta, J. Tomkinson, S. Rudic, R. S. Pinna, G. Gorini, J. Fernández Castañon, J. Phys. Conf. Series 2014, 554, 012003.

[19] http://www.isis.stfc.ac.uk/

[20] S. J. Clark, M. D. Segall, C. J. Pickard, P. J. Hasnip, M. J. Probert, K. Refson, M. C. Payne, Z. Kristallographie 2005, 220, 567-570.

[21] K. Refson, S. J. Clark, P. R. Tulip, Phys. Rev. B 2006, 73, 155114.

[22] A. Tkatchenko and M. Scheffler, Phys. Rev. Lett. 2009, 102, 073005.

[23] V. Milman, A. Perlov, K. Refson, S. J. Clark, J. Gavartin, B. Winkler. J. Phys.: Condens. Matter 2009, 21, 485404.

[24] http://accelrys.com/products/collaborative-science/biovia-materialsstudio/

[25] A. J. Ramirez-Cuesta, Comp. Phys. Comm. 2004, 157, 226-238. 


\section{SUPPORTING INFORMATION}

Title: Synthesis and inelastic neutron scattering spectroscopy of ruthenocene Author(s): Stewart F. Parker,* and Ian R. Butler

\section{Contents}

Page

Figure S1. Variable temperature $532 \mathrm{~nm}$ Raman spectra of ruthenocene.

Figure S2. Variable temperature $532 \mathrm{~nm}$ Raman spectra of ruthenocene. Same data as Figure S1, but with the $y$-axis on a logarithmic scale.

Figure S3. Correlation scheme for ruthenocene. Reproduced from: J. S. Bodenheimer, W. Low, Spectrochimica Acta Part A 1973, 29, 1733-1743, with permission of Elsevier.

Figure S4. Dispersion curves for ruthenocene generated from the lattice and geometry optimised structure.

Table S1. Calculated transition energies, mode number, symmetries and infrared and Raman intensities for ruthenocene in the lattice and geometry optimised Pnma structure. 


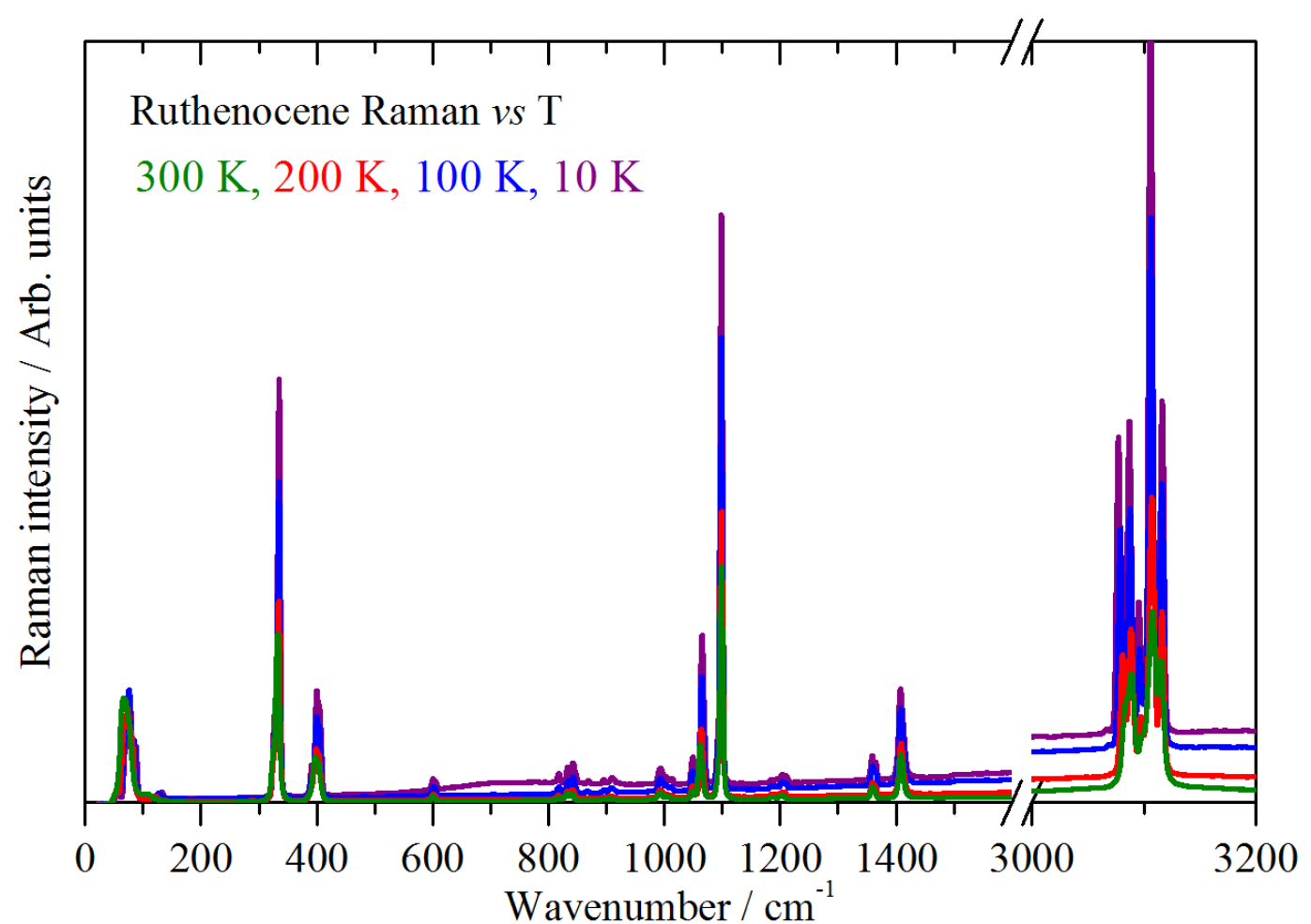

Figure S1. Variable temperature $532 \mathrm{~nm}$ Raman spectra of ruthenocene.

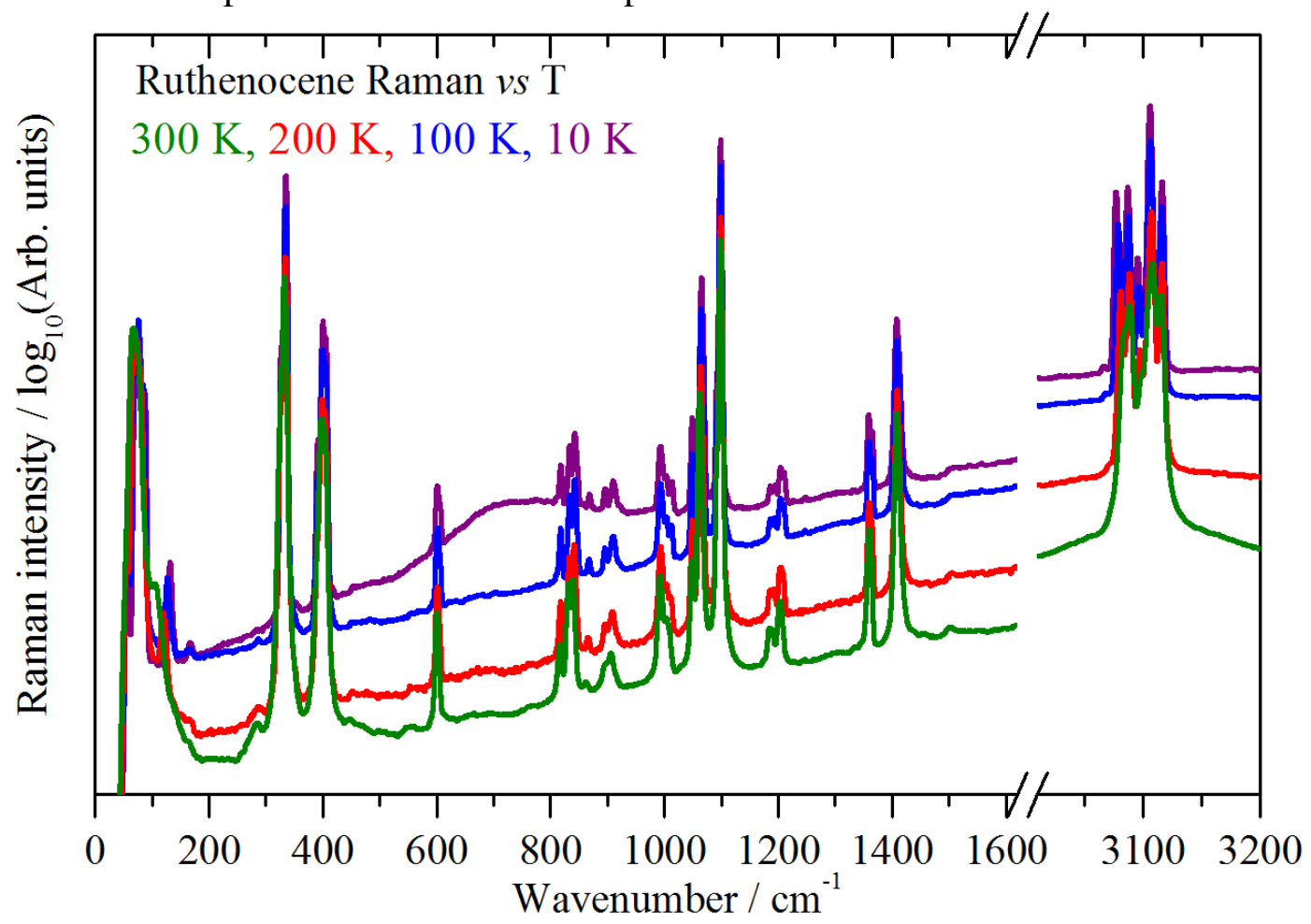

Figure S2. Variable temperature $532 \mathrm{~nm}$ Raman spectra of ruthenocene. Same data as Figure S1, but with the $y$-axis on a logarithmic scale. 


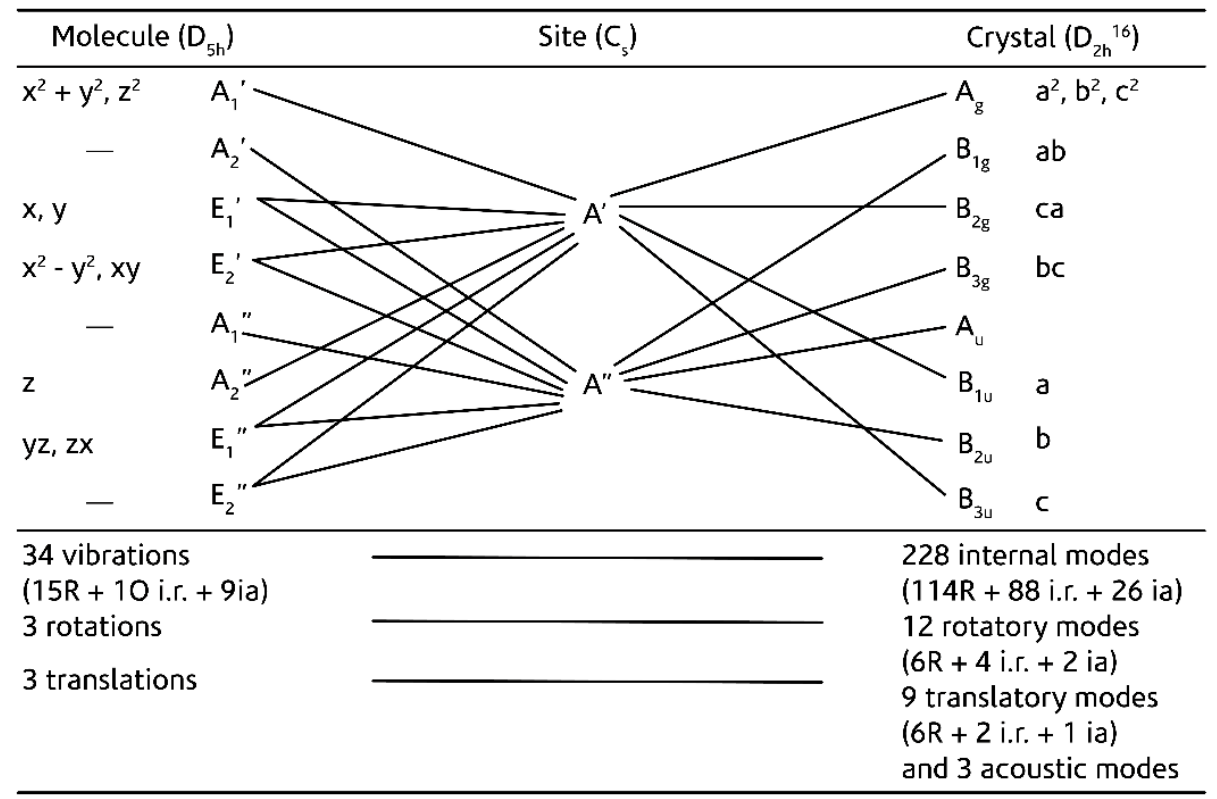

Figure S3. Correlation scheme for ruthenocene. Reproduced from: J. S. Bodenheimer, W. Low, Spectrochimica Acta Part A 1973, 29, 1733-1743, with permission of Elsevier. 


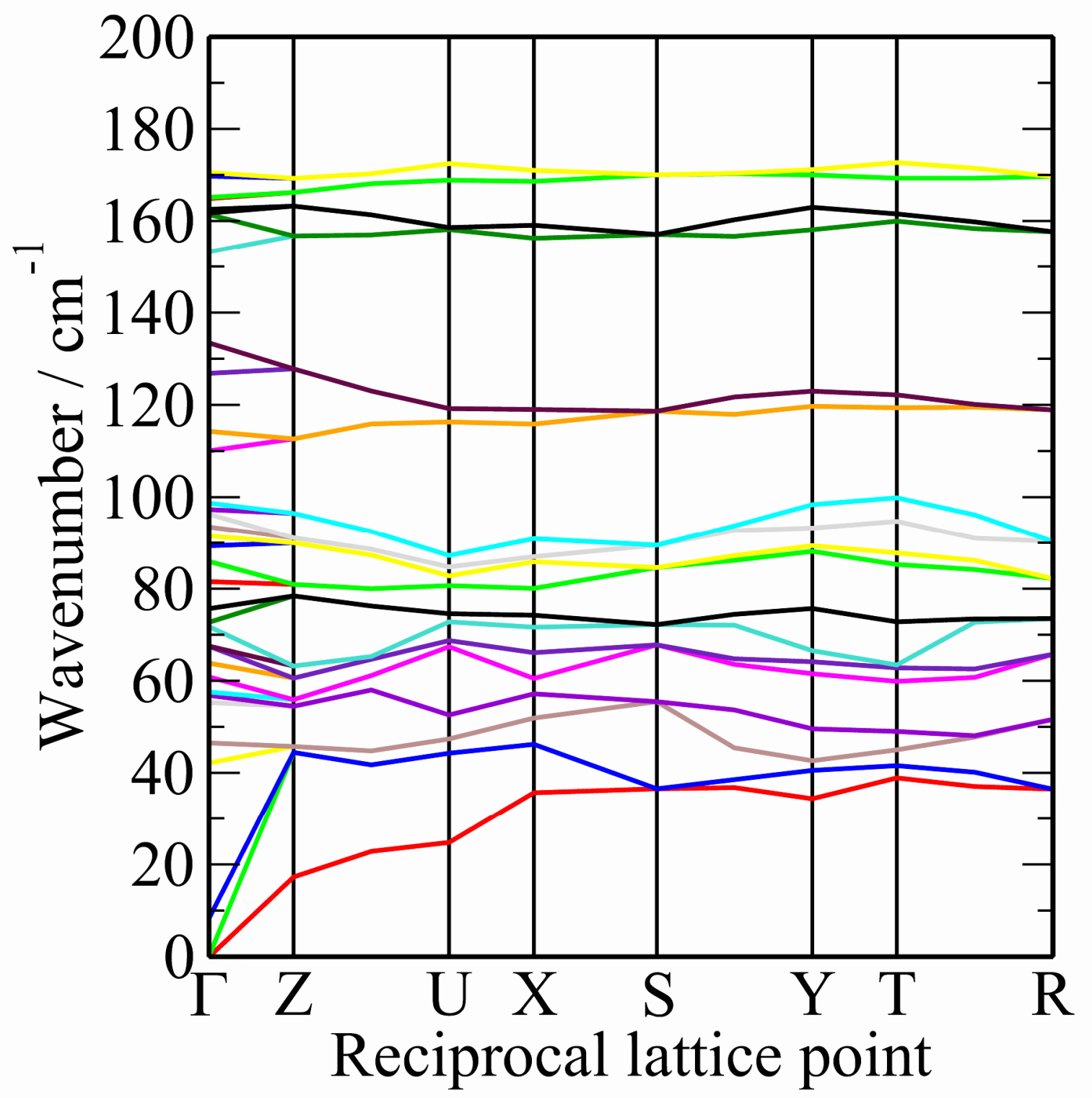

(a) 


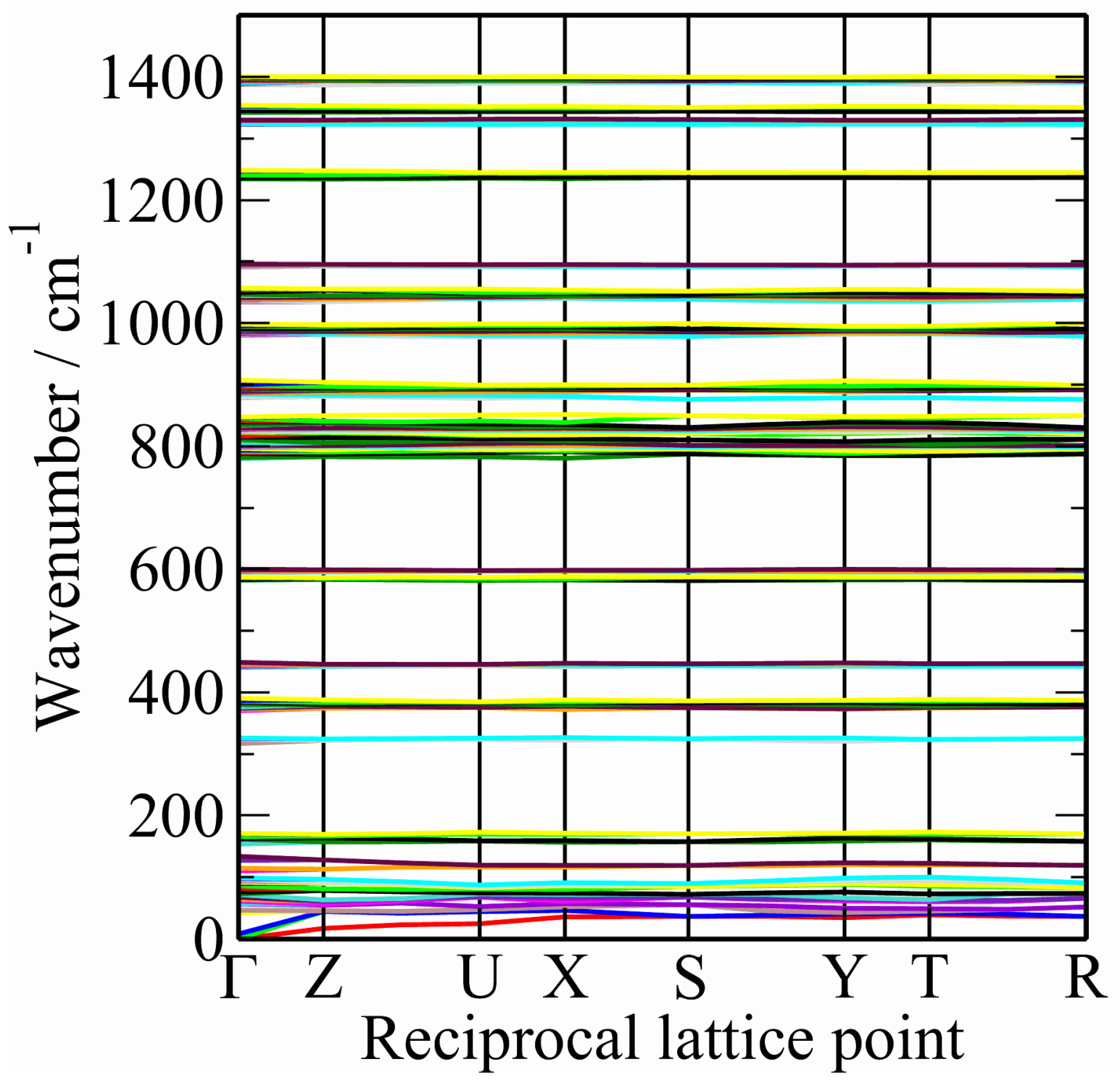

(b) 


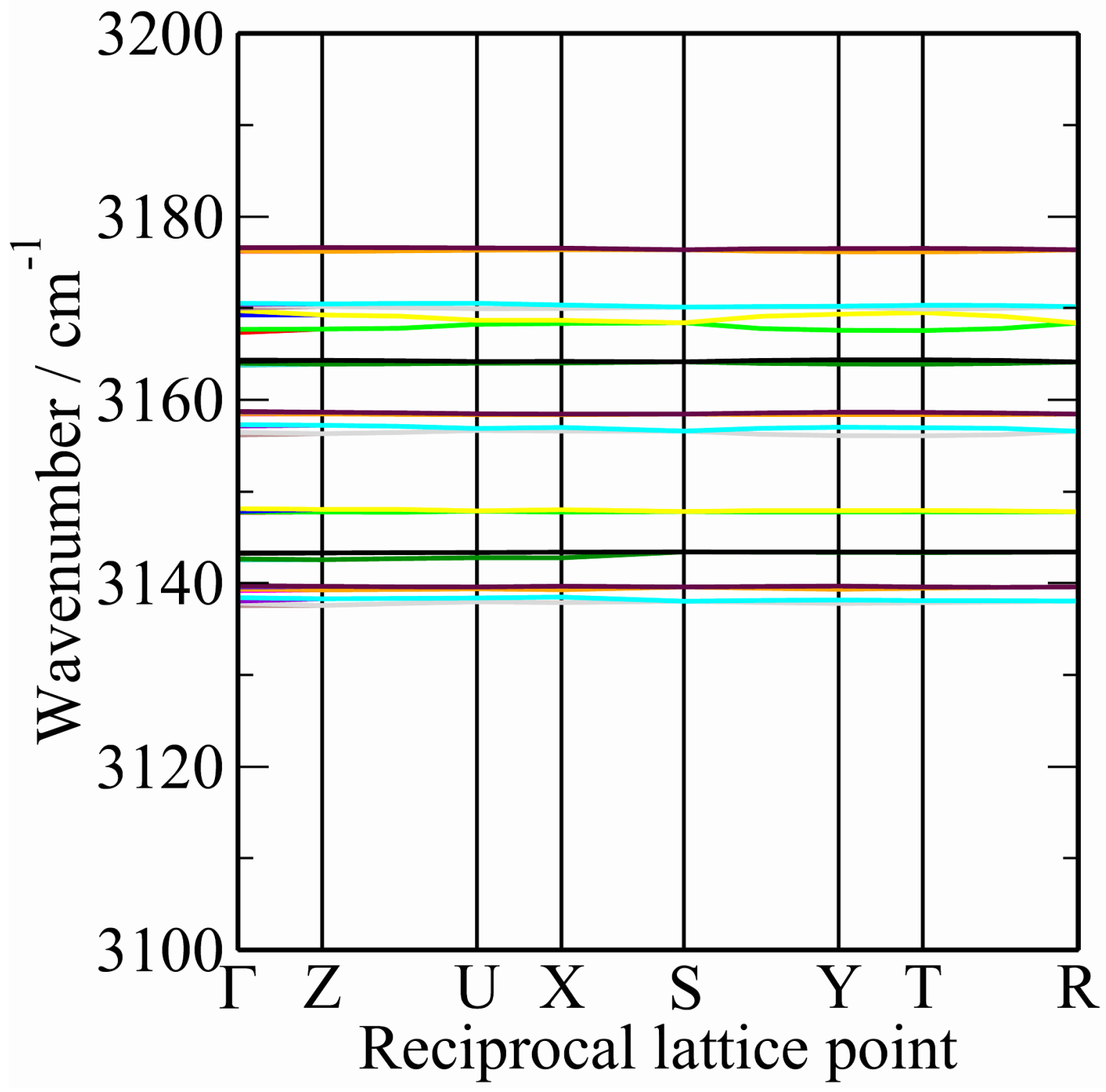

(c)

Figure S4. Dispersion curves for ruthenocene generated from the lattice and geometry optimised Pnma structure. (a) $0-200 \mathrm{~cm}^{-1}$, (a) $0-1500 \mathrm{~cm}^{-1}$, and (a) $3100-3200 \mathrm{~cm}^{-1}$. Note the absence of imaginary (negative frequency) modes. 
Table S1. Calculated transition energies, mode number, symmetries and infrared and Raman intensities for ruthenocene in the lattice and geometry optimised Pnma structure.

\begin{tabular}{|c|c|c|c|c|c|}
\hline $\begin{array}{l}\text { Transition } \\
\text { energy } / \mathrm{cm}^{-1}\end{array}$ & $\begin{array}{l}\text { Pnma } \\
\text { symmetry }\end{array}$ & $\begin{array}{l}\text { Mode } \\
\text { number for } \\
D_{5 \mathrm{~h}} \text { Structure }\end{array}$ & $D_{5 \mathrm{~h}}$ symmetry & $\begin{array}{l}\text { Infrared intensity } \\
\text { / (Debye } \AA^{-} \\
\left.{ }^{1}\right)^{2}(\text { amu })^{-1}\end{array}$ & $\begin{array}{l}\text { Raman } \\
\text { intensity } \\
/ \AA^{4} \\
(\text { amu })^{-1}\end{array}$ \\
\hline 0 & $\mathrm{~B} 3 \mathrm{u}$ & & & 0.00 & 0.00 \\
\hline 0 & B1u & & & 0.00 & 0.00 \\
\hline 0 & $\mathrm{~B} 2 \mathrm{u}$ & & & 0.00 & 0.00 \\
\hline 8 & $\mathrm{Au}$ & & & 0.00 & 0.00 \\
\hline 42 & B1g & 6 & A2" torsion & 0.00 & 2.87 \\
\hline 47 & $\mathrm{~B} 2 \mathrm{u}$ & & $\begin{array}{l}\text { ? Single ring } \\
\text { tors }\end{array}$ & 0.00 & 0.00 \\
\hline 55 & $\mathrm{~B} 1 \mathrm{u}$ & & a trans & 0.03 & 0.00 \\
\hline 57 & $\mathrm{Au}$ & & C2 Lib & 0.00 & 0.00 \\
\hline 58 & B3g & 6 & A2"torsion & 0.00 & 6.82 \\
\hline 61 & B2g & & c trans & 0.00 & 0.20 \\
\hline 64 & B3g & & $\begin{array}{l}\text { b trans or } \\
\text { lib? }\end{array}$ & 0.00 & 1.13 \\
\hline 67 & B1g & & $\begin{array}{l}\text { b trans or } \\
\text { lib? }\end{array}$ & 0.00 & 0.34 \\
\hline 68 & $\mathrm{Ag}$ & & c trans & 0.00 & 0.64 \\
\hline 72 & $\mathrm{~B} 3 \mathrm{u}$ & & c trans & 0.00 & 0.00 \\
\hline 73 & $\mathrm{~B} 2 \mathrm{u}$ & & $\begin{array}{l}\text { ? Single ring } \\
\text { tors }\end{array}$ & 0.10 & 0.00 \\
\hline 76 & $\mathrm{Au}$ & & $\begin{array}{l}\text { ? Single ring } \\
\text { tors }\end{array}$ & 0.00 & 0.00 \\
\hline 82 & $\mathrm{Ag}$ & & c trans & 0.00 & 8.03 \\
\hline 86 & $\mathrm{~B} 2 \mathrm{~g}$ & & a trans & 0.00 & 0.00 \\
\hline 89 & B1u & & C2 Lib & 0.00 & 0.00 \\
\hline 92 & B3g & & $\begin{array}{l}\text { ? Single ring } \\
\text { tors }\end{array}$ & 0.00 & 6.33 \\
\hline 93 & $\mathrm{Ag}$ & & C2 Lib & 0.00 & 50.43 \\
\hline 96 & $\mathrm{~B} 2 \mathrm{~g}$ & & C2 Lib & 0.00 & 19.30 \\
\hline 97 & B1g & & $\begin{array}{l}\text { ? Single ring } \\
\text { tors }\end{array}$ & 0.00 & 6.13 \\
\hline 99 & $\mathrm{~B} 3 \mathrm{u}$ & & C2 Lib & 0.02 & 0.00 \\
\hline 110 & $\mathrm{Au}$ & 6 & A2" torsion & 0.00 & 0.00 \\
\hline 114 & $\mathrm{~B} 2 \mathrm{u}$ & 6 & A2" torsion & 0.02 & 0.00 \\
\hline 127 & B3g & & C5 Lib & 0.00 & 10.79 \\
\hline 133 & B1g & & C5 Lib & 0.00 & 1.49 \\
\hline 153 & B3u & 21 & E1' & 1.18 & 0.00 \\
\hline 161 & $\mathrm{Ag}$ & 21 & E1' & 0.00 & 0.27 \\
\hline 162 & B1u & 21 & E1' & 0.07 & 0.00 \\
\hline 163 & B2g & 21 & E1' & 0.00 & 0.00 \\
\hline 165 & $\mathrm{Au}$ & 21 & E1' & 0.00 & 0.00 \\
\hline 165 & $\mathrm{~B} 2 \mathrm{u}$ & 21 & E1' & 1.66 & 0.00 \\
\hline 170 & B3g & 21 & E1' & 0.00 & 0.01 \\
\hline
\end{tabular}




\begin{tabular}{|c|c|c|c|c|c|}
\hline 171 & B1g & 21 & E1' & 0.00 & 0.00 \\
\hline 317 & $\mathrm{~B} 2 \mathrm{~g}$ & 4 & $\mathrm{~A} 1^{\prime}$ & 0.00 & 68.59 \\
\hline 324 & B1u & 4 & A1' & 0.00 & 0.00 \\
\hline 326 & $\mathrm{Ag}$ & 4 & A1' & 0.00 & 725.44 \\
\hline 326 & B3u & 4 & $A 1^{\prime}$ & 0.00 & 0.00 \\
\hline 370 & B3u & 11 & A2" & 0.01 & 0.00 \\
\hline 372 & B1u & 11 & A2" & 0.30 & 0.00 \\
\hline 374 & $\mathrm{Au}$ & 11 & A2" & 0.00 & 0.00 \\
\hline 376 & B3u & 11 & A2" & 0.03 & 0.00 \\
\hline 376 & $\mathrm{Ag}$ & 16 & E1" & 0.00 & 107.86 \\
\hline 381 & B2g & 16 & E1" & 0.00 & 9.86 \\
\hline 384 & $\mathrm{Ag}$ & 16 & E1" & 0.00 & 58.36 \\
\hline 385 & B1u & 16 & E1" & 0.01 & 0.00 \\
\hline 385 & B1g & 16 & E1" & 0.00 & 36.15 \\
\hline 386 & $\mathrm{~B} 2 \mathrm{~g}$ & 16 & E1" & 0.00 & 50.96 \\
\hline 387 & B2u & 16 & E1" & 0.10 & 0.00 \\
\hline 390 & B3g & 16 & E1" & 0.00 & 107.23 \\
\hline 440 & B3u & 22 & E1' & 4.92 & 0.00 \\
\hline 440 & B2u & 22 & E1' & 6.18 & 0.00 \\
\hline 441 & $\mathrm{Ag}$ & 22 & E1' & 0.00 & 0.30 \\
\hline 442 & B3g & 22 & E1' & 0.00 & 0.04 \\
\hline 443 & $\mathrm{Au}$ & 22 & E1' & 0.00 & 0.00 \\
\hline 444 & B1u & 22 & E1' & 1.98 & 0.00 \\
\hline 448 & $\mathrm{~B} 2 \mathrm{~g}$ & 22 & E1' & 0.00 & 0.20 \\
\hline 449 & B1g & 22 & E1' & 0.00 & 0.16 \\
\hline 582 & $\mathrm{~B} 2 \mathrm{~g}$ & 34 & E2" & 0.00 & 0.02 \\
\hline 582 & $\mathrm{Ag}$ & 34 & E2" & 0.00 & 3.20 \\
\hline 583 & B2u & 34 & E2" & 0.02 & 0.00 \\
\hline 585 & B1u & 34 & E2" & 0.00 & 0.00 \\
\hline 586 & $\mathrm{Au}$ & 34 & E2" & 0.00 & 0.00 \\
\hline 586 & B3g & 34 & E2" & 0.00 & 0.93 \\
\hline 587 & B1g & 34 & E2" & 0.00 & 0.87 \\
\hline 587 & B3u & 34 & E2" & 0.01 & 0.00 \\
\hline 594 & B3u & 28 & E2' & 0.00 & 0.00 \\
\hline 594 & B1u & 28 & E2' & 0.01 & 0.00 \\
\hline 595 & B1g & 28 & E2' & 0.00 & 0.82 \\
\hline 596 & $\mathrm{~B} 2 \mathrm{~g}$ & 28 & E2' & 0.00 & 9.65 \\
\hline 597 & $\mathrm{Ag}$ & 28 & E2' & 0.00 & 7.94 \\
\hline 597 & $\mathrm{~B} 2 \mathrm{u}$ & 28 & E2' & 0.01 & 0.00 \\
\hline 599 & $\mathrm{Au}$ & 28 & E2' & 0.00 & 0.00 \\
\hline 600 & B3g & 28 & E2' & 0.00 & 16.78 \\
\hline 780 & B3u & 14 & E1" & 0.31 & 0.00 \\
\hline 781 & B1u & 14 & E1" & 4.44 & 0.00 \\
\hline 786 & B1u & 9 & A2" & 9.11 & 0.00 \\
\hline 788 & $\mathrm{Ag}$ & 9 & A2" & 0.00 & 7.25 \\
\hline 789 & B2g & 9 & A2" & 0.00 & 2.02 \\
\hline 790 & B3u & 9 & A2" & 1.21 & 0.00 \\
\hline 794 & $\mathrm{Au}$ & 14 & E1" & 0.00 & 0.00 \\
\hline
\end{tabular}




\begin{tabular}{|c|c|c|c|c|c|}
\hline 797 & $\mathrm{~B} 2 \mathrm{u}$ & 33 & E2" & 0.02 & 0.00 \\
\hline 798 & B3u & 33 & E2" & 0.10 & 0.00 \\
\hline 799 & B2g & 33 & E2" & 0.00 & 5.06 \\
\hline 800 & $\mathrm{Au}$ & 33 & E2" & 0.00 & 0.00 \\
\hline 800 & $\mathrm{Ag}$ & 33 & E2" & 0.00 & 26.55 \\
\hline 801 & B1g & 33 & E2" & 0.00 & 1.04 \\
\hline 801 & B3g & 33 & E2" & 0.00 & 2.70 \\
\hline 802 & $\mathrm{~B} 2 \mathrm{u}$ & 14 & E1" & 0.18 & 0.00 \\
\hline 803 & $\mathrm{Ag}$ & 14 & E1" & 0.00 & 9.87 \\
\hline 804 & B1u & 33 & E2" & 0.49 & 0.00 \\
\hline 811 & $B 2 g$ & 2 & $\mathrm{~A} 1^{\prime}$ & 0.00 & 102.59 \\
\hline 815 & $\mathrm{~B} 3 \mathrm{u}$ & 2 & $\mathrm{~A} 1^{\prime}$ & 0.30 & 0.00 \\
\hline 815 & B1u & 2 & $\mathrm{~A} 1^{\prime}$ & 0.00 & 0.00 \\
\hline 816 & $\mathrm{Ag}$ & 2 & $\mathrm{~A} 1^{\prime}$ & 0.00 & 18.04 \\
\hline 823 & B1g & 14 & E1" & 0.00 & 0.50 \\
\hline 823 & B3u & 27 & E2' & 0.02 & 0.00 \\
\hline 823 & $B 2 g$ & 27 & E2' & 0.00 & 0.69 \\
\hline 824 & B3g & 14 & E1" & 0.00 & 21.07 \\
\hline 825 & $\mathrm{Ag}$ & 27 & E2' & 0.00 & 8.46 \\
\hline 827 & B1g & 27 & E2' & 0.00 & 2.59 \\
\hline 828 & $\mathrm{~B} 1 \mathrm{u}$ & 27 & E2' & 0.09 & 0.00 \\
\hline 828 & B3g & 27 & $E 2^{\prime}$ & 0.00 & 2.54 \\
\hline 829 & $\mathrm{~B} 2 \mathrm{u}$ & 27 & E2' & 0.03 & 0.00 \\
\hline 830 & $\mathrm{Au}$ & 27 & E2' & 0.00 & 0.00 \\
\hline 830 & B2g & 14 & E1" & 0.00 & 9.23 \\
\hline 834 & $\mathrm{~B} 3 \mathrm{u}$ & 19 & E1' & 0.00 & 0.00 \\
\hline 835 & B3g & 19 & E1' & 0.00 & 1.03 \\
\hline 840 & $\mathrm{Ag}$ & 19 & E1' & 0.00 & 0.54 \\
\hline 840 & $\mathrm{~B} 1 \mathrm{u}$ & 19 & E1' & 3.61 & 0.00 \\
\hline 842 & B2g & 19 & E1' & 0.00 & 8.24 \\
\hline 845 & B1g & 19 & E1' & 0.00 & 3.72 \\
\hline 846 & B2u & 19 & E1' & 0.00 & 0.00 \\
\hline 847 & $\mathrm{Au}$ & 19 & E1' & 0.00 & 0.00 \\
\hline 879 & $\mathrm{Ag}$ & 31 & E2" & 0.00 & 24.18 \\
\hline 879 & B2g & 31 & E2" & 0.00 & 0.32 \\
\hline 885 & B1g & 31 & E2" & 0.00 & 0.17 \\
\hline 885 & B3g & 31 & E2" & 0.00 & 2.95 \\
\hline 886 & $\mathrm{~B} 3 \mathrm{u}$ & 25 & E2' & 0.13 & 0.00 \\
\hline 886 & $\mathrm{~B} 2 \mathrm{u}$ & 31 & E2" & 0.20 & 0.00 \\
\hline 888 & B1u & 31 & E2" & 0.21 & 0.00 \\
\hline 891 & $\mathrm{~B} 3 \mathrm{u}$ & 31 & E2" & 0.17 & 0.00 \\
\hline 894 & $\mathrm{Au}$ & 31 & E2" & 0.00 & 0.00 \\
\hline 894 & $\mathrm{~B} 2 \mathrm{u}$ & 25 & E2' & 0.16 & 0.00 \\
\hline 894 & B1g & 25 & E2' & 0.00 & 23.06 \\
\hline 895 & B1u & 25 & E2' & 0.00 & 0.00 \\
\hline 895 & $\mathrm{Ag}$ & 25 & E2' & 0.00 & 5.22 \\
\hline 899 & $\mathrm{Au}$ & 25 & $E 2^{\prime}$ & 0.00 & 0.00 \\
\hline 900 & B2g & 25 & $E 2^{\prime}$ & 0.00 & 1.71 \\
\hline
\end{tabular}




\begin{tabular}{|c|c|c|c|c|c|}
\hline 907 & B3g & 25 & \begin{tabular}{|l|}
$E 2^{\prime}$ \\
\end{tabular} & 0.00 & 2.19 \\
\hline 980 & $\mathrm{Ag}$ & 13 & E1" & 0.00 & 15.16 \\
\hline 981 & B2u & 13 & E1" & 3.79 & 0.00 \\
\hline 982 & B1g & 13 & E1" & 0.00 & 36.14 \\
\hline 984 & B2g & 13 & E1" & 0.00 & 19.58 \\
\hline 984 & $\mathrm{Au}$ & 18 & E1' & 0.00 & 0.00 \\
\hline 985 & B1u & 13 & E1" & 0.06 & 0.00 \\
\hline 985 & B3u & 13 & E1" & 0.04 & 0.00 \\
\hline 988 & B3g & 13 & E1" & 0.00 & 28.65 \\
\hline 989 & B3g & 18 & E1' & 0.00 & 25.67 \\
\hline 989 & B3u & 18 & E1' & 4.38 & 0.00 \\
\hline 990 & $\mathrm{Au}$ & 13 & E1" & 0.00 & 0.00 \\
\hline 992 & B1u & 18 & E1' & 1.42 & 0.00 \\
\hline 994 & B1g & 18 & E1' & 0.00 & 0.00 \\
\hline 994 & $B 2 u$ & 18 & E1' & 1.84 & 0.00 \\
\hline 995 & B2g & 18 & E1' & 0.00 & 4.96 \\
\hline 998 & $\mathrm{Ag}$ & 18 & E1' & 0.00 & 25.33 \\
\hline 1034 & B3g & 30 & E2" & 0.00 & 0.06 \\
\hline 1037 & $B 2 u$ & 30 & E2" & 0.10 & 0.00 \\
\hline 1038 & B2g & 30 & E2" & 0.00 & 66.75 \\
\hline 1039 & B1g & 30 & E2" & 0.00 & 0.00 \\
\hline 1039 & $\mathrm{Ag}$ & 30 & E2" & 0.00 & 32.31 \\
\hline 1039 & B3u & 30 & E2" & 0.00 & 0.00 \\
\hline 1040 & $\mathrm{Au}$ & 30 & E2" & 0.00 & 0.00 \\
\hline 1042 & $\mathrm{Au}$ & 24 & E2' & 0.00 & 0.00 \\
\hline 1044 & B1u & 30 & E2" & 0.97 & 0.00 \\
\hline 1046 & $B 2 u$ & 24 & E2' & 0.08 & 0.00 \\
\hline 1049 & B1u & 24 & E2' & 0.12 & 0.00 \\
\hline 1052 & B1g & 24 & E2' & 0.00 & 424.93 \\
\hline 1054 & $\mathrm{Ag}$ & 24 & E2' & 0.00 & 284.20 \\
\hline 1055 & B3u & 24 & E2' & 0.30 & 0.00 \\
\hline 1056 & B3g & 24 & E2' & 0.00 & 105.66 \\
\hline 1057 & $B 2 g$ & 24 & E2' & 0.00 & 71.69 \\
\hline 1091 & B3u & 3 & A1' & 0.21 & 0.00 \\
\hline 1092 & B1u & 3 & A1' & 0.67 & 0.00 \\
\hline 1093 & $\mathrm{Ag}$ & 3 & A1' & 0.00 & 911.81 \\
\hline 1093 & B2g & 3 & A1' & 0.00 & 9.66 \\
\hline 1094 & B1u & 10 & A2" & 4.22 & 0.00 \\
\hline 1094 & $\mathrm{Ag}$ & 10 & A2" & 0.00 & 2382.24 \\
\hline 1095 & B2g & 10 & A2" & 0.00 & 13.36 \\
\hline 1095 & B3u & 10 & A2" & 1.14 & 0.00 \\
\hline 1234 & B1g & 5 & A1" & 0.00 & 3.85 \\
\hline 1235 & B3g & 5 & A1" & 0.00 & 0.32 \\
\hline 1237 & $\mathrm{Au}$ & 5 & A1" & 0.00 & 0.00 \\
\hline 1237 & $B 2 u$ & 5 & A1" & 0.50 & 0.00 \\
\hline 1241 & $\mathrm{Au}$ & 7 & $A 2^{\prime}$ & 0.00 & 0.00 \\
\hline 1241 & $B 2 u$ & 7 & $A 2^{\prime}$ & 0.81 & 0.00 \\
\hline 1247 & B3g & 7 & $A 2^{\prime}$ & 0.00 & 0.65 \\
\hline
\end{tabular}




\begin{tabular}{|c|c|c|c|c|c|}
\hline 1248 & B1g & 7 & $A 2^{\prime}$ & 0.00 & 0.28 \\
\hline 1323 & $B 2 u$ & 32 & E2" & 0.14 & 0.00 \\
\hline 1323 & $\mathrm{Au}$ & 32 & E2" & 0.00 & 0.00 \\
\hline 1323 & B3g & 32 & E2" & 0.00 & 0.02 \\
\hline 1324 & B1g & 32 & E2" & 0.00 & 0.02 \\
\hline 1329 & B2g & 32 & E2" & 0.00 & 1.80 \\
\hline 1329 & B1u & 32 & E2" & 0.32 & 0.00 \\
\hline 1330 & B3u & 32 & E2" & 0.00 & 0.00 \\
\hline 1330 & $\mathrm{Ag}$ & 32 & E2" & 0.00 & 4.28 \\
\hline 1342 & B1g & 26 & $E 2^{\prime}$ & 0.00 & 113.62 \\
\hline 1342 & B3g & 26 & E2' & 0.00 & 26.16 \\
\hline 1345 & B2u & 26 & $E 2^{\prime}$ & 0.00 & 0.00 \\
\hline 1345 & $\mathrm{Au}$ & 26 & E2' & 0.00 & 0.00 \\
\hline 1350 & B2g & 26 & $E 2^{\prime}$ & 0.00 & 31.27 \\
\hline 1351 & $\mathrm{Ag}$ & 26 & E2' & 0.00 & 71.84 \\
\hline 1352 & B1u & 26 & E2' & 0.00 & 0.00 \\
\hline 1354 & B3u & 26 & E2' & 0.08 & 0.00 \\
\hline 1388 & B1g & 15 & E1" & 0.00 & 73.94 \\
\hline 1389 & B3g & 15 & E1" & 0.00 & 20.29 \\
\hline 1389 & $\mathrm{Au}$ & 15 & E1" & 0.00 & 0.00 \\
\hline 1390 & $B 2 u$ & 15 & E1" & 1.39 & 0.00 \\
\hline 1393 & B3u & 15 & E1" & 1.80 & 0.00 \\
\hline 1394 & $\mathrm{Ag}$ & 15 & E1" & 0.00 & 398.19 \\
\hline 1394 & B1u & 15 & E1" & 0.94 & 0.00 \\
\hline 1395 & B2g & 15 & E1" & 0.00 & 74.90 \\
\hline 1398 & B2u & 20 & E1' & 0.04 & 0.00 \\
\hline 1398 & B1u & 20 & E1' & 0.16 & 0.00 \\
\hline 1398 & B3g & 20 & E1' & 0.00 & 208.88 \\
\hline 1398 & B3u & 20 & E1' & 0.03 & 0.00 \\
\hline 1398 & $\mathrm{Au}$ & 20 & E1' & 0.00 & 0.00 \\
\hline 1399 & $\mathrm{Ag}$ & 20 & E1' & 0.00 & 91.69 \\
\hline 1399 & B1g & 20 & E1' & 0.00 & 45.27 \\
\hline 1400 & $B 2 g$ & 20 & E1' & 0.00 & 48.18 \\
\hline 3138 & B1u & 29 & E2" & 0.16 & 0.00 \\
\hline 3138 & B3u & 29 & E2" & 0.83 & 0.00 \\
\hline 3138 & B2g & 29 & E2" & 0.00 & 16.51 \\
\hline 3138 & $\mathrm{Ag}$ & 29 & E2" & 0.00 & 1763.99 \\
\hline 3139 & $\mathrm{Au}$ & 29 & E2" & 0.00 & 0.00 \\
\hline 3139 & B3g & 29 & E2" & 0.00 & 8.13 \\
\hline 3140 & $B 2 u$ & 29 & E2" & 0.07 & 0.00 \\
\hline 3140 & B1g & 29 & E2" & 0.00 & 1149.73 \\
\hline 3143 & $B 2 u$ & 23 & E2' & 2.51 & 0.00 \\
\hline 3143 & $\mathrm{Au}$ & 23 & E2' & 0.00 & 0.00 \\
\hline 3143 & B1g & 23 & E2' & 0.00 & 2459.38 \\
\hline 3143 & B3g & 23 & E2' & 0.00 & 360.10 \\
\hline 3148 & B3u & 23 & E2' & 0.00 & 0.00 \\
\hline 3148 & B1u & 23 & E2' & 0.24 & 0.00 \\
\hline 3148 & B2g & 23 & E2' & 0.00 & 324.91 \\
\hline
\end{tabular}




\begin{tabular}{|c|c|c|c|c|c|}
\hline 3148 & $\mathrm{Ag}$ & 23 & E2' & 0.00 & 844.67 \\
\hline 3156 & $\mathrm{Ag}$ & 12 & E1" & 0.00 & 2913.73 \\
\hline 3156 & B3u & 12 & E1" & 0.01 & 0.00 \\
\hline 3157 & B1u & 12 & E1" & 0.18 & 0.00 \\
\hline 3157 & $B 2 g$ & 12 & E1" & 0.00 & 142.52 \\
\hline 3158 & $\mathrm{Au}$ & 12 & E1" & 0.00 & 0.00 \\
\hline 3159 & $\mathrm{~B} 3 \mathrm{~g}$ & 12 & E1" & 0.00 & 792.09 \\
\hline 3159 & $\mathrm{~B} 2 \mathrm{u}$ & 12 & E1" & 0.00 & 0.00 \\
\hline 3159 & $\mathrm{~B} 1 \mathrm{~g}$ & 12 & E1" & 0.00 & 4.84 \\
\hline 3164 & $\mathrm{~B} 2 \mathrm{u}$ & 17 & E1' & 0.09 & 0.00 \\
\hline 3164 & $\mathrm{~B} 1 \mathrm{~g}$ & 17 & E1' & 0.00 & 294.43 \\
\hline 3164 & $\mathrm{Au}$ & 17 & E1' & 0.00 & 0.00 \\
\hline 3164 & $\mathrm{~B} 3 \mathrm{~g}$ & 17 & E1' & 0.00 & 230.60 \\
\hline 3167 & $\mathrm{~B} 2 \mathrm{~g}$ & 17 & E1' & 0.00 & 1022.87 \\
\hline 3168 & B1u & 17 & E1' & 1.17 & 0.00 \\
\hline 3169 & $\mathrm{Ag}$ & 17 & E1' & 0.00 & 6598.43 \\
\hline 3170 & B3u & 17 & $\overline{E 1 '}$ & 0.17 & 0.00 \\
\hline 3170 & B3u & 8 & A2" & 0.06 & 0.00 \\
\hline 3170 & $B 2 g$ & 8 & $A 2^{\prime \prime}$ & 0.00 & 8.34 \\
\hline 3170 & B1u & 8 & $A 2 "$ & 0.00 & 0.00 \\
\hline 3171 & $\mathrm{Ag}$ & 8 & $A 2 "$ & 0.00 & 2468.22 \\
\hline 3176 & B3u & 1 & $A 1^{\prime}$ & 0.04 & 0.00 \\
\hline 3176 & $\mathrm{Ag}$ & 1 & $A 1^{\prime}$ & 0.00 & 5582.12 \\
\hline 3177 & B1u & 1 & $A 1^{\prime}$ & 0.15 & 0.00 \\
\hline 3177 & $B 2 g$ & 1 & $A 1^{\prime}$ & 0.00 & 933.39 \\
\hline
\end{tabular}

